TRANS · núm. $24 \cdot 2020$

MISCELÁNEA · 435-452
Durante la Alta Edad Media, el movimiento de traducción hacia el árabe, ya fuera transmisión directa ya indirecta, pero contando con la mediación de otras lenguas como el siríaco o el persa, no solo fue una cuestión de traslación de textos, sino un proceso de apropiación y transformación del conocimiento científico en un marco de aculturación inédito. En este contexto, se pretende contestar a la siguiente pregunta: ¿en qué medida la traducción contribuyó al desarrollo del pensamiento árabe-islámico del periodo clásico? Nuestras respuestas se elaborarán siguiendo un método analítico y crítico basado en fuentes escritas mayoritariamente en árabe. El estudio concluye con la aparición de dos bandos ideológicos en el seno de la cultura árabeislámica. Por un lado, los conservadores, que se apropiaron del legado de los "antepasados» (salaf)y de la producción traductológica; por otro, los moderados, que aspiraban a conquistar nuevos métodos de conocimiento independientemente de la herencia tradicional.

PALABRAS CLAVE: traducción, aculturación, griego, siríaco, persa,

árabe.

\title{
La traducción al árabe entre la mediación lingüística y la difícil asimilación cultural en el periodo abasî"
}

\author{
Abdallah Tagourramt El Kbaich \\ Universidad de Barcelona
}

\footnotetext{
* El presente artículo se enmarca en el proyecto de investigación "Género (s) y lenguaje (s) en la arabidad contemporánea” (PGC 2018100959-B-100), financiado por el Ministerio de Economía y Competitividad del Gobierno de España.
}

\section{The Translation into Arabic between Linguistic Mediation and the Difficult Cultural Assimilation in the Abbasid Period}

The translation movement of the Early Middle Ages, in which materials were translated into Arabic either directly or via the mediation of other languages such as Syriac or Persian, involved not just the translation of texts but also the appropriation and transformation of scientific knowledge in an unprecedented process of acculturation. Against this backdrop, the present study poses the following question: to what extent did translation contribute to the development of the Arab-islamic thought of the Classical period? We apply an analytical and critical method based on sources written mostly in Arabic. The study concludes with the emergence of two ideological camps inside Arab-islamic culture: on the one hand, the conservatives, who appropriated the cultural legacy of the "ancestors" (salaf) and the translations produced in a process of acculturation and assimilation; and on the other, the moderates, who sought to master new methods of knowledge independently of the traditional inheritance.

KEY WORDS: translation, acculturation, Greek, Syriac, Persian, Arabic. 


\section{INTRODUCCIÓN}

El pensamiento árabe-islámico ha sido objeto de varios estudios, escritos en árabe y en otras lenguas, marcados por infinitas discrepancias e interminables polémicas. Tal situación se debe obviamente a principios y objetivos de índole ideológica que se han desarrollado durante periodos de transición política y cultural. En este sentido, y contextualizando el enfoque de este artículo, cualquier aproximación a dicho pensamiento requiere tener en cuenta el impacto que ha tenido la traducción en su génesis, a partir de la llegada del islam. Por esta razón, es preferible establecer el punto de partida de dicho pensamiento a partir de la plasmación y la consolidación del Estado abasí. Tras ese acontecimiento, los árabes entraron en contacto progresivo con otras culturas del mundo clásico; lo que generó la necesidad de la traducción para comunicarse con los demás pueblos haciendo uso de sus experiencias, por una parte, y, por otra, para gestionar los asuntos políticos, económicos, religiosos y administrativos del nuevo Estado.

No obstante, eso no quiere decir que los árabes de la península arábiga vivieran antes del islam aislados de las demás culturas y tuviesen que esperar hasta la llegada de los califatos omeya (661-750) o abasí (750-1250) para abrirse al mundo. Al contrario, siempre mantuvieron contactos comerciales y espirituales con los pueblos que atravesaban la Península sobre todo durante los dos viajes que se hacían, una vez al año, en invierno hacia el sur y en verano hacia el norte. En ambos viajes se cruzaban culturas de Mesopotamia, de la India, del Cuerno Africano, de Grecia, etc. No obstante, tras la llegada del islam como nueva cultura los musulmanes y los pueblos islamizados mostraron un especial interés por la cultura de los «antiguos».

Como el Estado abasí se había convertido en un gran imperio, era necesario potenciar sus instituciones con la ciencia y el conocimiento, en tanto que medios, con la finalidad de mantener su propia estabilidad y de ese modo integrar su mosaico cultural y controlar los nuevos territorios conquistados. Eso estaba sucediendo cuando el árabe consiguió ser la lengua oficial del Estado abasí, tras la elaboración de sus componentes gramaticales, léxicos y sintácticos. Frente a esa nueva situación sociolingüística, las élites intelectuales que se convirtieron al islam o las que vivían bajo su bandera, empezaron a observar un notable retroceso de sus lenguas maternas frente a la expansión de la nueva lengua árabe. Asimismo, se dieron cuenta de que sus propias señas de identidad se iban perdiendo progresivamente. Por eso decidieron dedicarse a la traducción, para recuperar y reivindicar, de manera implícita, los valores identitarios integrantes de su patrimonio cultural. El persa 'Abd Allāh Ibn al-Muqaffa' y el siríaco Hunayn Ibn Ishāq son dos ejemplos destacados de esa experiencia traductora. En general traducían al árabe la filosofía griega desde sus respectivos idiomas y llegaron a marcar con sus métodos a toda una generación de traductores en sus entornos árabe-persa y árabe-siríaco.

Así pues, la traducción no solo fue un instrumento para responder a las necesidades pragmáticas y científicas, sino también una herramienta sociocultural para integrar la diversidad cultural de la sociedad árabe-islámica del Estado abasí. Fue también un medio que permitía a los traductores recontextualizar los textos de las fuentes originales apropiándose de ellos siguiendo un complejo proceso de transmisión y arabización exigido por los patrones de la traducción. De ese modo, la traducción pasó de ser una mera operación de transmisión de palabras e ideas de una lengua a otra a convertirse en un movimiento de aculturación inédito en la historia de la traducción en el ámbito cultural árabe-islámico. En este trabajo procedemos a analizar ese proceso 
de aculturación y apropiación teniendo en cuenta su efecto en el destino de las fuentes originales y en el devenir de la actividad traductora, de acuerdo con las hipótesis mencionadas en las fuentes clásicas y recogidas en las fuentes contemporáneas.

\section{EL DESTINO DE LAS FUENTES ORIGINALES}

Durante el periodo de la «registrografía» ${ }^{1}$ cultural árabe, gran parte de la cual tuvo lugar en los siglos VIII y IX, y dentro del que se integró el movimiento de traducción, se notaba al principio que dicho movimiento carecía de orden de índole estructural y temática. Es decir, no se seguía un plan coherente determinado a la hora de seleccionar los libros o los temas por traducir. Tampoco había preferencia dada por las culturas que iban a ser objeto de la operación traductora. No obstante, la traducción consiguió establecer sus bases científicas y ponerlas al servicio de la cultura árabe-islámica bajo el largo y amplio periodo del Estado abasí. Un Estado que nació en medio de tres civilizaciones muy arraigadas en la historia y cada una con sus propias peculiaridades: la griega, la hindú y la persa. Eran, pues, tres culturas hegemónicas a las que la cultura árabe-islámica hizo frente de manera sistemática para consolidar su existencia. Asistimos así a un contexto cultural emergente en el cual la traducción al árabe seguía un movimiento centrípeto para asimilar la savia de la ciencia griega, hindú y persa. Pero, aparte de asimilar la esencia de estas culturas, era necesario disimular las fuentes originales una vez realizada la traduc-

1 Según al-Ğābirī (2009: 63), este periodo llamado en árabe 'așr al-tadwīn representa el marco referencial de la cultura árabe-islámica tanto en el pasado como en el presente. La redacción y la clasificación de los libros, agrega al-Ğābirī, citando a Šams al-Dīn al-Dahabī (m. 1348), empezó en La Meca, Medina, la Gran Siria (al-Šām), Basora, Yemen y Kufa. ción. Es una tradición ${ }^{2}$ que encontramos también en otras civilizaciones como la helenística y que cita Dimitri Gutas:

When Alexander conquered the Kingdom of Dārā [Darius] the King, he had them all translated into the Greek language. Then he burnt the original copies which were kept in the treasure house of Dārā, and killed everyone whom he thought might be keeping away any of them. Except that some books were saved through the protection of those who safeguarded them. [...] Then when they returned to their homes after the death of Alexander they put into writing those parts that they had memorized. What they wrote down from memory was fragmentary. (Gutas 1998:37-38).

Por lo tanto, el hecho de no interesarse por las fuentes originales, o bien por guardarlas en vez de destruirlas, es un fenómeno que ya se manifiesta en tiempos remotos. En la cita de Gutas, vemos cómo la victoria militar de Alejandro Magno fue acompañada del saqueo cultural. Se apropió de ese botín cultural a través de la traducción al griego de una buena parte de los conocimientos racionalistas persas acumulados hasta el reino de Darío según la siguiente afirmación de Ibn Jaldún ${ }^{3}$ (2004: 249): «Para los persas las ciencias racionalistas desempeñaron un papel primordial. Habían sido muy desarrolladas porque las dinastías persas eran grandiosas y su poder nunca había sido interrumpido. Se decía que esas ciencias llegaron a Grecia cuando Alejandro Magno mató a Darío y derrotó al reino de los aqueménidas, apropiándose así de sus obras y de sus ciencias.»

2 Para más información sobre el hipotético destino de las fuentes originales - una vez acabada su traducción — en las culturas del mundo clásico, véase Ibn al-Nadīm (m. 995 o 998), Al-Fihrist (s. d.: 331-339).

3 Las traducciones al castellano de los textos citados en este artículo y cuya lengua original es el árabe son mías. 
438 Efectivamente, el factor tiempo y la estabilidad política desempeñaron un papel crucial en el esplendor de la civilización persa, sobre todo durante el dominio, primero de los aqueménidas (550-330 a. C.) y luego de los sasánidas (226-651 d. C.). Sin embargo, la derrota histórica de Darío frente a Alejandro Magno puso el punto final a la continuidad y a la grandiosidad del imperio aqueménida. Asimismo, dicha derrota prefiguró, mucho más tarde, lo que serían las conquistas islámicas a expensas de los sasánidas, lo que dio inicio a un nuevo ciclo cultural e ideológico en prácticamente toda Persia. En medio de esos cambios, que afectaban a las culturas y que coincidían con el método de Ibn Jaldún en su análisis del auge y declive de las civilizaciones, la traducción solía aparecer en primer plano. Se llevaba a cabo siguiendo una operación compleja antes de cumplir con la misión. Se seguían tres principales fases que procedo a citar bajo forma de tres preguntas: primero, ¿quién se ocupaba de seleccionar el material por traducir?; segundo, ¿quién asumía la traducción propiamente dicha?, y, tercero, ¿quién determinaba el destino de las fuentes originales? No se pretende contestar a cada uno de estos interrogantes, pero está claro que las instituciones políticas asumieron gran parte de ejecución de esas tres tareas. En efecto, los proyectos traductológicos, que se desarrollaban tras los contactos entre pueblos de varias culturas, tanto en tiempos de paz como en tiempos de guerra, se convertían a menudo en un asunto de Estado.

Además, existía otro fenómeno en virtud del cual la cultura árabe-islámica procedió, en algunos momentos, no solo a omitir fuentes originales de otras culturas, sino a rechazar traducirlas como ocurrió con las procedentes de la cultura persa. A eso se refería Ibn Jaldún en el capítulo XX de la Muqaddima, el titulado «Clasificación de las ciencias racionalistas», cuando menciona el destino de los libros de Persia tras la conquista islámica, que tuvo lugar durante el mandato de 'Umar Ibn al-Jațțāb, segundo califa del islam:

Cuando las tierras de Persia fueron conquistadas y se encontró en ellas una gran cantidad de libros, Sa 'd Ibn Abi Waqqāṣ, jefe del ejército de los musulmanes, mandó una epístola a 'Umar Ibn al-Jațțāb para consultar con él su destino y la posibilidad de transmitirlos a los musulmanes. 'Umar le contestó: «hay que tirarlos al agua. Si su contenido gira en torno a desarrollar una buena conducta, Dios nos ha guiado con mejores hábitos. Si su contenido es falsedad, Dios nos ha librado de ellos». Así se arrojaron los libros al agua o al fuego sin que la ciencia persa pudiera llegar a nosotros. (Ibn Jaldún 2004: 250).

Parece ser que se trata de una cita poco habitual si se tiene en cuenta que Ibn Jaldún era partidario de la cultura de los «antepasados» $(\text { salaf })^{4}$, que tenía que prevalecer sobre otros conocimientos fuera cual fuese el origen de estos. No obstante, si nos detenemos con atención en su contenido notaremos que encaja por completo con el método con el que Ibn Jaldún analiza el ciclo evolucionario de las civilizaciones a lo largo de la historia. Cada una tenía inicio y fin en medio de otras que marcaban el ritmo y la construcción identitaria y cultural de varios grupos humanos. Así pues, la conquista islámica de Persia

4 «Los antepasados» según los diccionarios de Ibn Manzūur y de al-Ğawharī. Este término se menciona en el Corán (43, 56): «fa-ğa'alnā-hum salafan wa matalan li-lāharinn» («Y sentamos con ellos un precedente, poniéndolos como ejemplo para la posteridad» [trad. Cortés]). En $E I^{l}$, alsalaf wa al-halaf: «los predecesores y los sucesores». Nombre dado respectivamente a las tres primeras generaciones y a las generaciones siguientes de la comunidad musulmana. En la sunna que ha establecido uno de los rasgos más característicos de la visión islámica de la historia, imponiendo la idea apriorística de que esta historia empezaría con una edad de oro que sería irremediablemente seguida de un periodo de aflojamiento, de desviación y, por último, de división (E. Chaumont, s. v. salaf.) 
tuvo lugar bajo el califato de 'Umar Ibn al-Jațțāb, quien mandó a arrojar al agua los libros del saber persa, rehusando la propuesta de Sa'd Ibn Abi Waqqāṣ, que consistía en transmitir dichos libros traduciéndolos, en vez de destruirlos. En aquel momento no se llevó a cabo la traducción del patrimonio persa sencillamente porque no había necesidad, ya que el islam, según el califa 'Umar, representaba el mensaje ideal, de dimensión universal, capaz de desarrollar una conducta completa.

El mismo fenómeno de supuesta omisión o de destrucción de las fuentes fue analizado, en otro contexto histórico y cultural, por el filósofo alemán Friedrich Schlegel (m. 1829), quien afirmó en un texto mencionado por Lacoue-Labarthe y Nancy:

Les arabes ont une nature au plus haut point polémique; entre toutes les autres, ils sont la nation annihilante. Leur manie de détruire ou jeter les originaux, une fois la traduction faite, caractérise l'esprit de leur philosophie. Pour cela même ils étaient peut-être infiniment plus cultivés, mais avec toute leurs cultures nettement plus barbares que les Européens du Moyen Âge. Barbare est en effet ce qui est à la fois anti-classique et anti-progressif. (Lacoue-Labarthe y Nancy 1978: 131).

Efectivamente Schlegel se refería a los árabes de los siglos IX y X, que lograron avanzar en importantes procesos de traducción a partir de la fundación de la Casa de la Sabiduría (Bayt alhikma) en Bagdad durante el reinado de al-Rašĩd (786-809) y de al-Ma'mūn (813-833). El postulado hecho de desembarazarse de los textos originales tenía dos explicaciones: primero, se trataba de evitar cualquier revisión de la traducción y, sobre todo, cualquier operación de re-traducción. Y como el movimiento de traducción en el periodo árabe clásico formaba parte del proyecto intelectual dedicado a la «registrografía» de la cultura, entonces la producción traductológica se debía integrar en los paradigmas de los salaf o «antepasados». Es decir, que las fuentes no se tenían que modificar una vez redactadas o traducidas sabiendo que en este caso la traducción se convertía, de alguna forma, en una operación de autoría. Y, si era preciso revisar o reexaminar algo, había que hacerlo de acuerdo con los criterios cognitivos establecidos por la cultura de los salaf. Adonis (1978: 9) lo explica así: «Los sucesores (jalaf) deben imitar a los salaf en su pensamiento y en su labor porque el califato representa la continuidad del pasado arraigado [...]. Y, cualquier esfuerzo creativo que surja, ha de ser a favor de la reafirmación del origen absoluto, sin añadir nada que pueda ser motivo de incertidumbre para cambiar y trascender dicha originalidad».

Volviendo a la cita de Schlegel, creemos que es necesario recordar la lectura que hizo de la misma 'Abd al-Salām Ibn 'Abd al-'Ālì mencionado por 'Abd al-Fattāḥ Kīlị̀̂u en un peculiar capítulo titulado «Lan tutarŷimanī» [No me traducirás] publicado en su libro Atakallamu ŷam $\bar{\imath}^{\prime}$ al-lugāt lākin bi-l-'arabiyya [Hablo todas las lenguas, pero en árabe].

Él [Schlegel] quería decir que la cultura árabe clásica cuando transmitía un texto a su lengua, lo adaptaba y lo incorporaba a sí misma. Lo admitía tras haber acabado con su aspecto exótico. Lo asimilaba y lo introducía en el área del ego creyendo así que ya no representaba al prójimo. Por eso, prescindía enseguida de él como fuente original una vez vertido en su lengua. (Kîlìțū 2013: 49-50).

Eso quiere decir que la traducción hacia el árabe en la Alta Edad Media era una operación de asimilación en la que la lengua árabe absorbía las fuentes originales igual que se hacía en otras culturas del mundo clásico. El objetivo principal que se perseguía en ese proceso traductológico 
440

consistía en la auto-reafirmación de la existencia de la cultura árabe-islámica; una cultura emergente tras haber superado la fase del registro patrimonial mencionado anteriormente. El hecho de superar dicha etapa no significaba transgredir las bases de la cultura de los salaf, sino se trataba de una manera de consolidar los pilares del pensamiento árabe-islámico de la época. Por lo tanto, destruir las fuentes originales una vez acabada la traducción, según Schlegel, o prescindir de ellas tras haberlas adoptado y adaptado, según la interpretación de Ibn 'Abd al-'Ālī lleva a dar por sentado que los eruditos y los traductores árabes del periodo de la «registrografía» cultural y de la traducción procuraban, en la medida de lo posible, construir un proyecto de civilización completamente revolucionario e innovador. Para llevar a cabo esa complicada labor, era menester romper con los modelos clásicos, tanto de origen árabe (patrimonio cultural preislámico u omeya, por ejemplo) como de origen no árabe (grecorromano, hindú y persa). Todos esos factores fueron introducidos en la sociedad árabe-islámica a través de la traducción, sometida a diversos controles ejercidos directamente por la propia institución califal abasí. De modo que la omisión de las fuentes originales era un procedimiento que se seguía para apropiarse de ellas y para tomarlas como origen propio. Por lo tanto, gracias a dicha apropiación que se hacía a través de la traducción, la civilización árabe aspiraba a conseguir su objetivo principal, que consistía en apropiarse de la historia para establecer su supremacía sobre toda la historia universal durante la Edad Media 5 .

5 Para más información sobre la apropiación de la historia por los árabes, véase el libro de 'Abd al-Salām Cheddādī (2004): Les arabes et l'appropriation de l'histoire. Émergences et premiers développements de l'historiographie musulmane jusqu'au IIe-VIIIe siècle, Arles: Sindbad/Actes Sud.

\section{TRADUCCIÓN DE LA FILOSOFÍA GRIEGA Y APROPIACIÓN DE LAS FUENTES ORIGINALES}

La filosofía forma parte de las ciencias racionalistas ${ }^{6}$, clasificadas por Ibn Jaldún en cuatro categorías: «la lógica, las ciencias naturales, la metafísica y las artes liberales (la geometría, la aritmética, la música y la astronomía)». Pero la producción traductora de dichas disciplinas del saber, del griego al árabe, de modo directo o indirecto, contando con la mediación del siríaco o del persa, enseguida se convirtió, según Abd al-Raḥmān (1995: 82) en una fuente original y la propia filosofía en una mera rama de saber. Se trata de una operación paradójica en la cual las fuentes filosóficas originales dejaron de ser originales y pasaron a ocupar un rango secundario en el pensamiento árabe-islámico del periodo clásico; sin embargo, la traducción ocupó un escalón principal en dicho pensamiento. Estamos así ante un claro proceso de apropiación en el que la traducción al árabe se hacía para conseguir dos objetivos principales: primero, traducir y, segundo, apropiarse de lo traducido en la medida en que la materia traducida respondiera y sirviera a los mecanismos constructivos de la cultura árabe-islámica en estado emergente. Ahora bien, este proceso de apropiación, que se ejecutaba manipulando las fuentes originales, convertiría la filosofía árabe-islámica en una filosofía dependiente y el pensamiento quedaría subordinado a diferentes corrientes ideológicas que soplaban desde varias culturas circundantes. Por su parte, dichas corrientes iban a dar lugar al nacimiento de varias ideologías desde

6 O forma parte de la lógica según el catálogo de alFārābī (1949: 53-74) elaborado en el siglo X. Lo mismo hizo Ibn Hazm (1987: 131), al asociar la ciencia de los antiguos con la filosofía y la lógica. 
dentro tras el proceso de arabización que se seguía en la transmisión de los textos.

En el ámbito árabe-islámico, solo se puede hablar de filosofía, propiamente dicha, a partir de las primeras transmisiones al árabe de la filosofía griega, desde el griego directamente o a través de otras lenguas, sobre todo el siríaco y el persa. Lo único que había antes de iniciarse el proyecto de traducción de la filosofía griega eran las ideas expresadas bajo la forma de refranes y dichos árabes calificados de sabiduría árabe antigua. En este contexto, Ṭaha 'Abd al-Raḥmān afirmó que:

Antes de esta traducción [de la filosofía griega], sólo existía un conocimiento que los historiadores se negaban clasificar dentro de la filosofía. Se trata de lo que se llamaba «la sabiduría árabe», unos conocimientos fruto de experiencias prácticas que sus autores formulaban bajo forma de dichos y refranes retóricos en los que no encontramos la abstracción racional, ni el orden lógico como hallamos en la traducción filosófica. Esos historiadores excluían dicho conocimiento del círculo de la filosofía hasta que se amplió el significado de «la sabiduría» que se convirtió en sinónimo de «filosofía». ('Abd al-Raḥmān 1995: 83)

El único pensamiento del cual se podía hablar era la ciencia islámica recopilada en árabe y clasificada en fiqh (jurisprudencia,), hadiz, tafsīr (interpretación del Corán) y fiqh al-luga (la ciencia del lenguaje). Por lo tanto, la traducción de la filosofía griega, que no empezó hasta el reinado del califa al-Manșūr y alcanzó su auge durante el reinado del califa al-Ma'mūn, constituiría un acontecimiento crucial para el futuro del pensamiento árabe-islámico. Primero, los árabes empezaron a adquirir una perspectiva abstracta fuera del círculo habitual establecido por los «antepasados» o salaf durante el periodo de la «registrografía» cultural. Segundo, dicha perspectiva iba a generar en la vida intelectual una serie de polémicas que concluyeron con la aparición de dos tendencias ideológicas yuxtapuestas: una de rumbo modernizador, y otra de orientación conservadora. De este modo, se produjo la primera división en la cultura de los salaf. Según el mismo Ṭ. 'Abd al-Raḥmān, esta división se debía a lo siguiente:

Los árabes no conocieron la teoría filosófica abstracta y sistemática excepto a través de las primeras traducciones de los libros de la filosofía griega. En este caso, aquellas traducciones pasaron por varias dificultades relacionadas con la ambigüedad de su significado [...] y todo eso influyó, sin duda, en el ejercicio teórico que los árabes hacían frente a esa nueva manera de ver las cosas [...]. Asimismo, [esas traducciones] generaron más discrepancias entre el pensamiento filosófico griego y el pensamiento árabe-islámico [...]. Lo que generó una extrema confrontación por parte de los diferentes grupos conservadores contra la filosofía griega. ('Abd al-Raḥmān 1995: 85)

Frente a esa nueva realidad cultural, los intelectuales de la época abasí intentaban experimentar nuevas ideas procedentes de la filosofía griega a través de la traducción. Pero la gran dificultad a la cual se enfrentó ese proceso experimental consistía — según sostenía 'Abd al-Raḥmān - en que al principio la filosofía dependía, de manera relevante, de la traducción. Se sumó a esa dependencia, el problema de la confusión lingüística desde el punto de vista de los significados. Muchos traductores no habían logrado traducir correctamente los textos filosóficos por su naturaleza compleja o por falta de especialización por parte de los mismos traductores. Eso provocó en los usuarios de la lengua árabe de aquel entonces un cierto desasosiego que generó más discrepancias entre la filosofía griega y el pensamiento árabe-islámico. Este último rehusó ser dependiente de la primera que, 
442 a su vez, fue absorbida por los criterios traductológicos vinculados directamente con los fundamentos de la cultura de los «antepasados» (salaf). Hemos de recordar que la traducción era un movimiento cultural que formaba parte del proyecto intelectual árabe elaborado durante la fase de la «registrografía» cultural. Se registró en consecuencia un intento de toma de conciencia que pretendía refutar la filosofía griega derivada de unas traducciones erróneas, incompletas o simplemente manipuladas. Por esa razón, los interesados en la filosofía griega como Avicena (m. 1037) y Averroes (m. 1198) decidieron corregir y regenerar las traducciones y los comentarios de estas para liberar los textos de la «confusión de la expresión de los traductores» (qalaq 'ibārat almutarğimīn), según postulaba al-Ğābirī (2000: 508). De este modo, el pensamiento árabeislámico podía dejar de imitar servilmente y depender de la filosofía griega transmitida por unos traductores patrocinados por los mecenas de la corriente de los «antepasados».

\section{MEDIACIÓN DEL SIRÍACO}

La traducción al siríaco del patrimonio cultural griego se remonta a tiempos preislámicos. Entre los acontecimientos de esa larga época sería conveniente destacar las conquistas de Alejandro Magno, ya que, según Aḥmad al-Dubyān:

La cultura griega se difundió por todo Oriente $\mathrm{y}$, consecuentemente, aquello generó cambios fundamentales a lo largo de la historia política y cultural. Las regiones circundantes del Mediterráneo pasaron a estar bajo la hegemonía romana o bizantina, mientras que los persas fundaron un potente Estado en Persia. Por su parte, al-Šām se convirtió en una zona de sucesivas guerras entre los persas y los bizantinos. Estos acontecimientos y fluctuaciones ocasionaron cierta diversidad cultural en aquella zona. Por eso, las lenguas fueron objeto de interés por parte de los pueblos asentados, de acuerdo con las circunstancias políticas y las influencias culturales que las enmarcaban. (alDubyān 1993: 19).

Dentro de este marco histórico, que duró siglos, las lenguas desempeñaron un papel relevante para establecer canales de comunicación entre los pueblos de Mesopotamia, de al-Šām, es decir, la Gran Siria, y del Mediterráneo en general. El peso de una lengua se medía en aquel entonces en virtud de la potencia política y el valor cultural de cada civilización. En este contexto destacaba la hegemonía del griego, que se convirtió durante mucho tiempo en lengua propia de la cultura, la ciencia y la filosofía; mientras que los dialectos arameos representaban el lenguaje principal de las masas. La situación siguió así hasta que el griego empezó a perder terreno gracias a la emergencia del imperio romano, que asimiló la civilización griega y comenzó a entrar en contacto con las culturas adyacentes. La ciudad de Edesa aprovechó aquellos cambios históricos para extender su influencia en las provincias del norte de Siria e Irak. Su lengua llegó a dominar sobre los demás dialectos arameos de aquellas zonas para convertirse más tarde en una lengua llamada siríaco. En este contexto, Ġazāl Mūsà Yūnān Murād afirma que:

El idioma siríaco había sido la principal fuente de la cual los traductores transmitieron al árabe la filosofía. Los siríacos habían estado en contacto con la cultura griega durante muchos siglos y se dedicaron, dos siglos antes de la llegada del islam, a traducir a su lengua la filosofía griega y preservarla en sus libros y en sus bibliotecas estudiándola en sus escuelas, en sus monasterios y en sus iglesias. Así, continuaron este método de traducción, de preservación y de estudio incluso después de haber entrado en contacto con los árabes y el ingreso en su propia civilización. (Yūnān Murād, apud 'Abd al-Raḥmān 1995: 92). 
Así pues, en aquellas regiones septentrionales de la Gran Siria y Mesopotamia el siríaco se convirtió en la lengua de la civilización cristiana con sus diferentes elementos constituyentes: griego, persa, árabe, etc. Pero ¿cómo fue valorada aquella traducción al siríaco de la filosofía griega? Según Ahmad Amīn (2011a [1928]: 147): «Aquellos siríacos traducían las ciencias griegas con precisión y fidelidad [...], sobre todo la lógica, la física, la medicina y las matemáticas. En cuanto a las ciencias religiosas, se modificaban de acuerdo con el cristianismo.»

Los siríacos, pues, difundieron la filosofía griega en Irak y en sus alrededores durante el califato abasí. En cuanto a la traducción de los asuntos religiosos, se hacía en función de las exigencias de la religión cristiana, puesto que uno de los motivos de la traducción era religioso. En cuanto se trataba de religión, los traductores procedían de otra manera y actuaban con mucha cautela. Lo mismo hicieron, más tarde, los traductores musulmanes, que dejaron de traducir textos o pasajes por ser incongruentes con las instrucciones del islam. Pero este fenómeno, presente de diferentes maneras tanto en la cultura grecorromana como en la árabe-islámica, hizo que dichas culturas entrasen en conflicto ideológico continuo con el patrimonio filosófico griego no solo por razones religiosas, sino por otros motivos sociolingüísticos y traductológicos. Por ejemplo, a los traductores al árabe de la filosofía griega, tanto los siríacos como los árabes en las primeras fases del movimiento traductológico que se estaba elaborando bajo el reinado del califato abasí, les era difícil, según Ṭ. 'Abd al-Rahmān, liberarse de la confrontación en la cual estaban involucrados:

Esas notables diferencias y esas discrepancias relevantes en las cuales habían caído los traductores se debían a varios motivos, como la falta del dominio del árabe y, eso generaba en ellos la 443 debilidad del instinto lingüístico árabe [al-salīqa al-lugawiyya], la ignorancia del contenido de la religión islámica y el desconocimiento del método científico para entender el islam. Además, hemos de tener en cuenta que la lengua materna de la mayoría de aquellos traductores era el siríaco y su religión, en general, era la cristiana. Por eso, sus primeras traducciones eran prosaicas, desde el punto de vista estilístico, y, en cuanto al contenido, inmaduras [...]. Asimismo, adoptaron un método de traducción basado en la posibilidad de expresar en la lengua meta cualquier significado una vez extraído de su contexto original. Igualmente, creían que las experiencias de las personas en el universo eran únicas e idénticas sus doctrinas ideológicas y que su manera de entender las cosas era homogénea. ('Abd al-Raḥmān 1995: 84-85).

Ṭ. 'Abd al-Raḥmān, desde el ángulo del filósofo musulmán, y centrando sus investigaciones científicas en la lógica y en la filosofía del lenguaje, pone de manifiesto en este largo fragmento una serie de componentes que distorsionaron los inicios de la trayectoria de la traducción en el islam. Podemos distinguir entre factores objetivos y factores ideológicos. Por una parte, es obvio que los traductores siríacos y los traductores árabes después, no dominaban lo que 'Abd alRaḥmān llama «al-salīqa al-lugawiyya» (instintivo lingüístico) que caracterizaba la lengua del beduino árabe, «constructor de la razón árabe» según al-Ğābirī (2009), es decir, constructor de la auténtica cultura lingüística fundamentada sobre «la claridad y la aclaración» si utilizamos, en otro contexto, la terminología de al-Ğāhiz (1998). Por otra parte, continúa 'Abd al-Raḥmān insistiendo sobre una serie de elementos de sumo interés. Ahora orienta sus opiniones críticas directamente hacia la traducción y subraya el hecho de tomar la habilidad traductológica como práctica natural del lenguaje. Asimismo, 
444 critica en los traductores la falta de suficientes conocimientos religiosos y culturales de la lengua meta, el árabe en este caso. Y no le falta razón, puesto que en la traducción la lengua es la cultura y la cultura es la lengua; son dos caras de la misma moneda. Además, los traductores siríacos prestaban mucha atención a la lengua original, bien fuese su propia lengua, bien el griego, para llevar a cabo la operación traductora hacia el árabe. Por lo tanto, el problema ya no estaba relacionado con el «instinto lingüístico», sino más bien con los conocimientos culturales que conectaban la lengua con la religión. Por último, 'Abd al-Raḥmān califica aquellas traducciones de inmaduras, literales y superficiales. Es un fenómeno debido a que los traductores siríacos de la época, pese a su innegable labor transmisora, creían desde una perspectiva humanística en la homogeneidad de las experiencias humanas, cuando las lenguas y las culturas eran múltiples, diversas y se esparcieron por toda la tierra desde la mítica Torre de Babel.

Aun así, podemos decir que los traductores siríacos desempeñaron un papel esencial al capacitar la lengua árabe para que asimilara y acogiera una gran cantidad de vocablos procedentes de la ciencia y de la filosofía griega. Es cierto que no siempre acertaron en su tarea traductora, debido a la evolución lingüística y a la relación discrepante que siempre hubo entre los intérpretes del texto coránico y los propios traductores de la filosofía helénica. Por ejemplo, a nivel social y según Albert Hourani:

La ciencia fue aceptada sin dificultad por la cultura y la sociedad y se expresaban en árabe [...]. Los médicos eran, en general, respetados y lograron influir en los gobernantes. Sin embargo, algunas de las ciencias planteaban interrogaciones acerca de los límites del conocimiento humano [...] ya que, en ciertos aspectos, los métodos y las conclusiones de la filosofía griega parecían difíciles de reconciliar con las enseñanzas básicas del islam, tal y como las desarrollaban teólogos y juristas. (Hourani 1992: 58-59).

Estas últimas discrepancias mencionadas por Hourani se debían tal vez a la confusión y a la ambigüedad que caracterizaban varias traducciones efectuadas a base de la mediación de otras lenguas. En la medida en que la traducción se hacía a través de una o dos lenguas se incrementaba la distancia entre el texto original y el texto meta. A la luz de ese método, que se siguió durante mucho tiempo entre la primera generación de traductores, la pérdida de mucha información de primera utilidad era obviamente irremediable. Cuando se perdía la información de base por el motivo que fuera, se ponía en entredicho la labor traductora y supuestamente la cultura y el conocimiento que se pretendía transmitir. A eso se debe el que los críticos de la traducción expresaran explícitamente su aversión frente a esas primeras traducciones deficientes. En este contexto, cabe recordar el famoso debate, narrado por Abū Ḥayyān al-Tawhịīī (m. 1023), que se produjo entre Abū Sa'īd al-Sīrāfī (m. 979), gramático, jurista musulmán de origen persa, y Abū Bišr Mattā Ibn Yūsuf (m. 940), nestoriano asirio, filósofo y traductor de Aristóteles:

AbūSa'īd dijo: «jEntonces no nos invitas a aprender la lógica, sino a cursar griego y tú no sabes griego! ¿Cómo se te ha ocurrido invitarnos a aprender una lengua en la cual ya no confiábamos? Hacía mucho tiempo que desapareció y se extinguieron sus hablantes [...] y tú traduciendo del siríaco, ¿qué opinas sobre unos significados transmitidos del griego al siríaco y de este al árabe?». Mattā contestó: «Aunque los griegos desaparecieron con su lengua, la traducción ha cumplido con los objetivos marcados, transmitiendo los significados y siendo fiel a la verdad». Abū Sa 'īd replicó: «Eso siempre que aceptásemos que la traducción ha sido fiel y no ha traicionado al original. [...]. Con 
todo eso, parecía que nos estuvieras diciendo que no existía otro argumento que no fuera la razón griega». (al-Tawhīīī 1929: 71-72).

En este texto, cargado de opiniones de alTawḥ̂̄ī sobre los intelectuales de su tiempo, se aprecia la existencia de una moral dialogante entre dos personajes representativos de la cultura cristiana nestoriana y la persa-islámica, haciendo de la lengua árabe el vínculo de comunicación para debatir sobre temas lingüísticos, traductológicos y filosóficos. Asimismo, conviene subrayar el uso del estilo directo plagado de expresiones satíricas y argumentativas. Todo ello tenía como objetivo atestiguar la relación conflictiva que había entre la élite de los lingüistas y gramáticos persas de la lengua árabe, por un lado, y, por otro, la élite de los traductores nestorianos que se encargaron de la traducción al árabe de la filosofía griega. La raíz de la polémica en cuestión consistía en la divergencia que había entre la lógica griega y la retórica árabe. Es por esta razón por la que al-Sīrāfī expresó sus opiniones subrayando la vanidad de la traducción, que no era capaz de ser fiel a las reglas de la elocuencia árabe. Además, la operación traductológica se hacía del griego al árabe a través del siríaco, sin olvidar que se estaba traduciendo del griego arcaico, en el cual no confiaba el alfaquí persa. En realidad, no es que al-Sīrāfī no confiara en el griego de tiempos remotos, sino que su incertidumbre iba dirigida hacia la labor de los traductores, que no siempre acertaron en el proceso de transmisión hacia el árabe. Así pues, el Órganon nunca fue transmitido al árabe tal como se redactó en su fuente original. Con esas afirmaciones, pues, podemos averiguar la verdadera intención de al-Sīrāfī, su convicción de la imposibilidad de la traducción de la lógica griega. En cambio, Mattā sostenía que la traducción cumplía con sus deberes y no importaba el declive de la lengua de la Antigua Grecia. Para él, si el esplendor científico y filosófico griego había desaparecido de donde se originó, seguía aún vivo en los «archivos de traducción», tanto siríacos como árabes.

Como resultado de la polémica, llegamos a la idea de que al-Sīrāfī, desde su posición de alfaquí y gramático, pretendía valorar negativamente los resultados del movimiento de traducción considerando que la lógica, sobre todo la aristotélica, era una disciplina ajena a la cultura árabe-islámica. Pero detrás de este juicio, fácil de detectar a simple vista en la cita que estamos analizando, había una intención implícita de alSīrāfī. Como nos encontramos entre finales del siglo X y principios del XI, es preciso señalar que se trata de una época trascendental en la trayectoria del pensamiento árabe-islámico que se desarrollaba entre las fuerzas de los salaf, los partidarios de los «antepasados» conservadores, y de los halaf «sucesores», que eran innovadores. Los primeros llamaron a imitar la tradición recopilada durante el periodo de la «registrografía» cultural elaborada junto con el movimiento de traducción. En cambio, los segundos abogaban por trascender la imitación del patrimonio cultural de los primeros para pasar a la autoría sin tener asimilado que — según al-Sīrāfī_ pudiera existir «otro argumento que no fuera la razón griega.»

\section{MEDIACIÓN DEL PERSA}

La lengua persa desempeñó también un papel intermediario en la transmisión al árabe de la filosofía griega. Dicho papel, según la valoración de Ibn al-Nadīm, se limitó a algunas obras de lógica y medicina. En este contexto sostenía que «antiguamente, fueron traducidos al persa algunos libros de lógica y medicina que 'Abd Allāh Ibn al-Muqaffa' y otros traductores transmitieron al árabe» (S.F: 22). No obstante, este papel no alcanzó el nivel de mediación del siríaco que he- 
446

mos mencionado en el apartado anterior porque según al-Dubyān (1993: 50), los persas no eran especialistas en ciencias, sino en literatura, en historia y en política. La actividad científica que habían desarrollado en Gundeshapur, fue gracias a los médicos siríacos que ya habían asimilado el patrimonio científico griego e hindú. Esos contactos entre el siríaco y el persa generaron una mediación lingüística que llegó a convertirse en una cadena de transmisión y que 'Abd alRaḥmān comentó de la siguiente manera:

La mediación entre los originales escritos en griego y las traducciones al árabe se convirtió en una mediación diversa o, mejor dicho, compleja. Como el siríaco hacía de intermediario entre el griego y la traducción persa, fue evidente que la traducción al árabe se hiciera también desde el persa, precedida de una traducción desde el siríaco al cual se había transmitido inicialmente el original griego. ('Abd al-Raḥmān 1995: 93).

Así pues, la traducción al árabe de la filosofía griega se sometió en varias ocasiones a esa doble intermediación siríaco-persa. Si decimos doble intermediación, hemos de tener en cuenta los dos imaginarios lingüísticos propios de cada una de las dos culturas. Justamente asíla cultura del islam se ponía en contacto con la cultura de los traductores siríaco-persas, por un lado, y con la del legado que procedía de la sabiduría griega a través de estos mismos traductores, por otro.

En efecto, el movimiento traductor de la época desempeñó un papel fundamental en el tejido de la cultura árabe bajo el califato abasí. Dicha cultura incluía en su fase de construcción el combinado de cuatro elementos principales: el griego, el siríaco, el persa y el árabe de acuerdo con Carl Brockelmann, citado por Aḥmad Amīn:

Según Brockelmann, la península arábiga e Irak fueron influidos por la civilización griega. Había en los monasterios siríacos varios libros traducidos no solo sobre el cristianismo [...], sino también traducciones de Aristóteles, de Galeno y de Hipócrates [...], y los siríacos eran los transmisores de la cultura griega al imperio persa de los sasánidas [...]. Así empezó esa semilla griega a crecer hasta la llegada de los abasíes. (Amīn: 2011b [1933]: 424).

Muchas fuentes árabes consideraban el persa como elemento básico en la construcción de la cultura árabe bajo la bandera del islam. Esta construcción se basó en dos dinámicas estrechamente correlacionadas: la traducción y la autoría; la traducción del griego al persa y de este al árabe y la autoría en árabe ejercida por varios eruditos de origen persa. Muchos de ellos destacaron en ciencias del lenguaje, en jurisprudencia, en historia y en literatura. A eso se refería Ibn Jaldún (2004: 361) cuando afirmó que «la mayoría de los eruditos en el islam eran 'ağam [es decir, persas], tanto en las ciencias religiosas como en las ciencias racionales, excepto algunos casos muy limitados». Y lo justificaba afirmando que las ciencias formaban parte de los oficios de áreas urbanas, mientras que los árabes eran beduinos. En consecuencia, los 'ağam eran los productores de las ciencias. Asimismo, el autor de la Muqaddima respaldaba su opinión con el siguiente hadiz: «Si la ciencia se colgara sobre las alas del cielo, sería alcanzada por la gente de Persia» (Ibn Jaldún 2004: 362).

A pesar de lo preciso y justificado de la observación jalduniana, es desproporcionada porque encierra un juicio de valor difícil de aceptar en medio de una sociedad árabe-islámica de aspecto híbrido. Por consiguiente, la hipótesis de considerar a los árabes como beduinos y por ello incapaces de elaborar ciencias parece inoportuna, sobre todo a partir de la llegada del islam y de las conquistas de territorios fuera de la península arábiga. Los musulmanes persas, 
árabes o procedentes de otras culturas tenían el compromiso de cumplir con las instrucciones de su religión. Entre estas, figura el buscar la ciencia por todos los caminos lícitos del saber y establecidos por la sharía, ya que el islam es un mensaje que pretende ser universal. Asimismo, es un discurso que insta a los fieles a buscar conocimiento en general, como viene mencionado en las tres siguientes aleyas del Corán ${ }^{7}$ :

I. Y di: «¡Señor! ¡Aumenta mi ciencia!» (20: 114).

2. Dios también eleve la categoría de aquéllos de vosotros que crean y reciban la ciencia. (11: 20).

3. Pero nadie sino Dios conoce la interpretación de ello. Los arraigados en la ciencia dicen: «Creemos en ello. Todo procede de nuestro Señor.» (3: 7).

Aun así, los 'ăgam o extranjeros en general y sobre todo los persas, desempeñaron un papel primordial en el proyecto de la «registrografía» cultural por el motivo que hemos presentado antes con Ibn Jaldún. Los persas eran autores y herederos de una civilización ancestral y cuando se convirtieron al islam aprendieron árabe y continuaron su labor de autoría y creación en esa lengua siguiendo los métodos persas. En general, su papel de transmisión junto con la operación de autoría y de creación tuvo, según Gutas (1998: 25), una importante repercusión:

Translations from Greek in to Pahlavi, i.e., the Middle Persian of the Sasanians and from Pahlavi into Arabic constitute a very significant and often underrated factor in the development not only of the 'Abbāsid Graeco-Arabic translation movement but also of Arabic literature and culture in general.

Al principio de esta labor traductora persa,

\footnotetext{
Las traducciones al castellano de las aleyas mencionadas en este trabajo son de J. Cortés.
}

que se remonta incluso a la época preislámica, 447 cabe señalar los factores ideológicos que había detrás de muchas figuras de la ilustración persa. Dichos factores los resume el propio Gutas:

There are first the pre-Islamic translations into Pahlavi of Greek scientific and possibly philosophical works. The Sasanian interest in Greek learning was partly also motivated by a Zoroastrian imperial ideology that would see all learning ultimately derived from the Avesta ${ }^{8}$, the Zoroastrian canonical scripture [...]. (Gutas 1998: 25).

Aparte de ese factor ideológico interno, los persas junto con las demás figuras ilustres procedentes de otras culturas, como los siríacos compaginaban la tarea de traducción con la de autoría y creación en árabe en prácticamente todas las tierras del islam. La redacción en árabe era una realidad lingüística a la cual se habían enfrentado los 'ă̆am para expresarse y para defender sus ideales aspirando a encontrar el lugar que les correspondía en medio de la diversidad cultural del islam. Redactar directamente en árabe era seguir un nuevo método para traducir las propias ideas sin que fuera necesario tener en cuenta la lengua de partida, tanto la original como la intermediaria, por ejemplo, el griego, el siríaco, o el persa. Pero, a pesar de esa autonomía lograda en la redacción, la cultura que conllevaban estas lenguas siempre estaría presente en la producción intelectual árabe. La redacción directamente en árabe era para los traductores

8 Según al-Mas'ūì̄ī (2005: 175), este libro del zoroastrismo, que encierra todas las ciencias del universo, está escrito en una lengua inédita y difícil de interpretar. El propio profeta Zoroastro se encargó de elaborar una primera interpretación y más tarde una segunda. Añade al-Mas'ūì̄ì que el Avesta estaba compuesto de doce mil volúmenes. En general, su temática giraba en torno a las normas canónicas y espirituales que los reyes persas aplicaron hasta la caída de Persia frente a Alejandro Magno, circunstancia que provocó la quema de gran parte del libro. 
448 un compromiso impuesto, sobre todo, desde el punto de vista político e ideológico, ya que, según Aḥmad Amīn:

El Estado político era árabe con sus califas, su lengua y su religión. Asimismo, el Estado de la literatura era árabe y sólo cabía en él lo que era árabe. Por eso, todas las figuras literarias, científicas y lingüísticas debían aprender la lengua árabe para tejer en ella sus ideas, su literatura y su saber. El que dominaba la ciencia griega debía expresar su saber en árabe y el que tenía amplios conocimientos de literatura persa estaría desprovisto de méritos si no expresaba su literatura en árabe. Un matemático o médico hindú debía arabizar su saber si quería gozar de suficiente reconocimiento, etc. (Amin 2011b [1933]: 336).

Por consiguiente, escribir directamente en árabe, sobre todo para los persas, en distintas disciplinas del saber constituiría un acontecimiento de gran impacto en la historia de la ciencia árabe. La autoría en árabe protagonizada por los 'ă̆am, por una parte, reconsideraba el papel cultural de estos en la sociedad según la afirmación de Amín, y, por otra, alteraría el sendero del pensamiento árabe-islámico marcando un antes y un después. Primero, la sharía como ciencia religiosa dejaría paulatinamente de ser propiedad del sunismo y en ella se abrirían canales interpretativos de orientación chií. Seguidamente, estas convergencias y divergencias entre los propios suníes, por una parte, y entre estos y los chiíes, por otra, darían lugar a la aparición de cuatro escuelas jurídicas para asumir la interpretación del islam: la hanafí, la šāfi'i, la mālikí y la ḥanbalí. A estas se añadiría la doctrina ğa'farí cuya orientación es estrictamente chií. Segundo, la autoría directamente en árabe empezaría a restar protagonismo al movimiento traductor que retrocedería progresivamente hasta su desaparición casi total en los albores del siglo XI.
Fue un factor debido a la nueva realidad que se vivía desde el punto de vista intelectual, ideológico y político. La cultura árabe-islámica de entonces parecía haber conseguido su autonomía para continuar construyéndose a sí misma sin necesidad de cualquier papel intermediario que pudieran desempeñar otras lenguas dentro del proceso de la traducción.

\section{PLASMACIÓN DE LA RAZÓN ÁRABE Y EL DESTINO DE LA TRADUCCIÓN}

Durante el periodo abasí, gran parte de las ciencias griegas fueron transmitidas al árabe a través del siríaco o directamente desde el griego, sobre todo por Ḥunayn Ibn Ishạa y su círculo de traductores. Asimismo, las literaturas persa e hindú fueron traducidas al árabe, destacando en este contexto, la labor traductora de Ibn al-Muqaffa'. También, gracias a la traducción, al-Ma'mūn introdujo en su reino el factor ideológico confesional. Convirtió el mu'tazilismo en la doctrina oficial del Estado abasí. De hecho, Ibn al-Nadīm (s. d.: 168) lo tilda, en su Al-Fihrist, de ser «el califa más versado en jurisprudencia y de teología dogmática y escolástica» (a'lam al-ḩulafâ' bi-lfiqh wa-l-kalām). Por lo tanto, el encuentro, que había sido posible gracias a la traducción, entre el racionalismo griego y la razón ${ }^{9}$ en la cultura árabe-islámica, marcó durante los siglos IX y X el triunfo del debate entre ambas culturas, por una parte, y, por otra, perfiló el avance del propio movimiento de traducción que influyó a su vez en la evolución de la vida intelectual árabe-islámica. No obstante, el impacto de este movimiento de traducción se convirtió en una gran paradoja. Por un lado, contribuyó a la plasmación de

9 Entendiendo la razón, según al-Ğābirī (2009: 37), como «conjunto de principios y normas que ofrece la cultura árabe a los que pertenecen a ella como fundamento para adquirir conocimiento». 
la razón árabe, y, por consiguiente, a moldear los cinco principios teóricos del pensamiento mu'tazilí. Por otro, este mismo mu'tazilismo, que sobrevivió durante varios periodos históricos comprendidos entre los inicios del siglo VIII y finales del siglo $\mathrm{X}$-destacando el periodo de al-Ma'mūn-, iba a ser una de las principales causas del fin del movimiento de traducción. En contrapartida, esta constituiría uno de los factores principales del fin del mu'tazilismo y obligatoriamente de la «dimisión de la razón árabe», haciendo uso de la terminología de al-Ğābirī, o de la «destitución de la razón árabe», usando la terminología de Ṭarābīšš quien considera:

El mismo mu'tazilismo de al-Ma'mūn que abrió, por completo, la puerta al movimiento de traducción se iba a traducir en un pretexto para los adversarios del propio mu ' tazilismo y de la filosofía para así volver a cerrar aquella puerta. Así pues, el contexto mu'tazilí en medio del cual se desarrolló el movimiento de traducción desde su nacimiento se convertiría en un elemento conminatorio permanente, como si de una maldición se tratara, que llevó a ese movimiento a su fin. (Ṭarābīš̄̄ 2006: 45).

Este destino irreversible tanto del movimiento de la traducción como de la corriente racionalista mu'tazilí marcaría el devenir del pensamiento árabe oriental posterior. En vez de que este continuase su curso natural y recreara lo que tenía entre las manos de acuerdo con el espíritu de la época, se fugó hacia el pasado cultural salafí creado durante el periodo de la «registrografía» cultural. Asistimos de este modo al triunfo histórico de la tradición religiosa $(a l-n a q l)$ sobre la razón ( $a l$-'aql). Además, apareció en el escenario cultural de la época el fenómeno de la supuesta quema de libros traducidos que contenían las «ciencias de los antiguos» lo que implica para Tarābī̌̌ī el inexorable final de la actividad tra- ductora en el islam:

El movimiento de traducción fue enterrado vivo y se preparó de modo sistemático la quema de los libros indeseables de ciencia y de libros traducidos. No obstante, ese fenómeno no fue considerado una práctica exclusiva de los gobernantes, sino se extendió también a las masas instigadas por los alfaquíes extremistas. Durante el grave conflicto, que duró dos siglos, entre los suníes y chiíes de Bagdad fueron calcinadas muchas bibliotecas y varios depósitos de libros ${ }^{10}[. .$.$] . Ese fenómeno de$ la quema de los libros se extendió fuera del Mashreq y alcanzó el Magreb ${ }^{11}$, donde el pensamiento mu'tazilí se había desarrollado poco. A pesar de ello, los alfaquíes malikíes declararon la guerra contra los libros de las «ciencias de los antiguos», del mismo modo que lo hicieron los alfaquíes hanbalies en el Mashreq ${ }^{12}$. (Ṭarābīš̄i 2006: 47-49).

Como se aprecia, este texto está plagado de expresiones extremas desde el punto de vista crítico. Si queremos utilizar una traducción literal de los vocablos de dichas expresiones tendremos, por ejemplo: «enterrar viva a la traducción» (wa'd al-tarğama), «un verdadero holocausto» (mihraqa haqiqiyya); «los alfaquíes extremistas» (al-muta'așibìn min al-fuqahā'), «la inveterada

Io Para más información sobre esa discordia entre suníes y chiíes, véase: Ibn al-Ațīr (s. d.: 335).

II En este mismo contexto, Julio Samsó (2011: 71) afirma que este hecho «se relaciona con la quema de la biblioteca del al-Hakam II ordenada por al-Manșūr (g. 981-1002) con el fin de congraciarse la simpatía de los alfaquíes conservadores. De acuerdo con el testimonio de Sa ${ }^{\text {î }} \mathrm{d}$ de Toledo se procedió a un previo expurgo de la misma que muestra que las iras del sector tradicional iban dirigidas en contra de las ciencias de los antiguos" ('ulūm al-awā'il).»

12 Véase Șā'id al-Andalusī (1912: 66-67). Además, cabe mencionar que el Ándalus no vivió ningún movimiento destacado de traducción hacia el árabe, sino un movimiento de traducción directa del árabe al latín y a las lenguas romances o del árabe a estas a través del hebreo, hecho histórico que contribuyó en la construcción del Renacimiento europeo. Véase también Aḥmad 'Itmān (2013: 430-465). 
450

discordia» (al-fitna al-muzmina), «los alfaquíes malikíes y hanbalíes lideraron la guerra contra la ciencia de los antiguos» (adāra fuqah̄̄' almālikiyya wa al-ḥanbaliyya al-ḩarba diḍda 'ulūm $a l$-'awā'il). Todos estos recursos lingüísticos usados por el intelectual sirio mantienen una relación intrínseca y metodológica con el título de un capítulo titulado: «¿Quién acabó con la traducción en el islam?» en este libro, Hartaqāt [Herejías]. En concreto, el fragmento que acabamos de citar responde a esta pregunta haciendo hincapié en los principales factores que obstaculizaron el movimiento de traducción en el seno del pensamiento árabe-islámico. ¿No se trataría entonces de una campaña histórica y sistemática contra la ciencia racional de los antiguos bajo el lema proverbial: «quien a la lógica se dedica herético ha de ser» (man tamantaqa, tazandaqa)? Evidentemente, sus protagonistas eran gobernantes y alfaquíes hanbalíes y malikíes que adoctrinaban a las masas, añadiendo a eso el conflicto perdurable confesional suní-chií. De modo que fueron los factores políticos y confesionales los que frenaron la continuidad del movimiento de traducción y, en consecuencia, el desarrollo de la ciencia racionalista transmitida a la cultura árabe-islámica tanto en el oriente como en el occidente islámicos. No obstante, este paralelismo que hizo Ṭarābīš̄ entre la traducción y la razón en el Magreb y el Mashreq deja mucho que desear, sobre todo en lo que concierne al tema del desarrollo posterior de la razón y la lógica. En el Mashreq asistimos hacia finales del siglo XI a una derrota total de la razón debida a la supuesta quema de las traducciones de la ciencia racionalista de «los antiguos». A ese fenómeno le siguió el cierre de «la puerta del esfuerzo interpretativo» (bāb al-iğtihād). En cambio, en el Magreb se inició, en la misma época histórica, una relectura de las traducciones y de las interpretaciones de los textos filosóficos de Aristóteles.

\section{CONCLUSIONES}

A modo de conclusión, el movimiento de traducción hacia el árabe marcó el proceso de plasmación de la cultura árabe-islámica en la Alta Edad Media. Durante el periodo de la «registrografía» cultural árabe, que empezó hacia la segunda mitad del siglo VIII, los califas abasíes decidieron establecer, por escrito, el canon cultural que determinaría el pasado, el presente y el futuro de su Estado. Para conseguir dicho objetivo, se produjeron dos procesos de transmisión que cambiaron la vida cultural de la época. En primer lugar, se trasladó gran parte de la oralidad árabe preislámica que trataba sobre «los Días de los árabes» basándose en las aportaciones de la voz beduina. Dentro del mismo proceso, se redactó la jurisprudencia y el hadiz para facilitar la interpretación del Corán. Y, en segundo lugar, se transmitió al árabe «la ciencia de los antiguos» para integrar la diversidad cultural del Estado del islam. Al principio, el proceso traductor estaba basado en la mediación de otras lenguas, sobre todo el siríaco y el persa. En medio de ese fenómeno de intermediación, la traducción de esas ciencias se sometió a un doble proceso de adaptación. Por una parte, fue cristianizada por los traductores siríacos nestorianos y, por otra, fue islamizada - a base de esta cristianización- gracias al control de la demanda traductora que los mecenas abasíes ejercían sobre cualquier proyecto de traducción.

Dentro de ese círculo de intermediación lingüística y cultural, se urdió el tejido del pensamiento árabe-islámico, que no solo se contentó con conseguir los objetivos pragmáticos de la traducción, sino que también procedió a integrar todo lo que dimanaba de otras culturas en el proyecto de construcción cultural. Se trata de una operación de aculturación de gran enverga- 
dura, que dio lugar a las primeras teorías de la traducción establecidas por al-Ğāhiz en el ámbito árabe-islámico. Asimismo, dio lugar a una gran controversia entre dos movimientos ideológicos que marcarían las fases posteriores del pensamiento árabe-islámico. Por un lado, estaba el dogma de los partidarios de los salaf o «antepasados», que decidieron apropiarse de la herencia cultural recopilada y redactada durante el periodo de la «registrografía» cultural; por otro, la idiosincrasia de los partidarios de los halaf o «sucesores», que optaron por trascender la doctrina salafí para conquistar nuevos métodos de adquirir el conocimiento. Creían que los eruditos de la cultura tradicional se centraron, al elaborar su proyecto cultural, en la transmisión de la cultura oral y de varios libros escritos en otras lenguas, sin tener en cuenta las grandes crisis políticas y espirituales del mundo clásico. Además, la mediación lingüística durante el proceso traductor del griego al árabe, pese a su innegable papel intercultural, fue un factor decisivo que llevó al pensamiento árabe-islámico a fluir, directa o indirectamente, entre la imitación y la dependencia durante muchos siglos.

Así pues, la traducción no solo fue un instrumento para responder a necesidades pragmáticas y científicas, sino también una herramienta sociocultural para integrar la diversidad cultural de la sociedad árabe-islámica del Estado abasí. Fue también un medio que permitía a los traductores recontextualizar los textos y los contextos de las fuentes originales y apropiarse de ellos siguiendo un complejo proceso de transmisión y arabización exigido por los mecenas de la época. En algunas épocas esta apropiación cultural tuvo que hacer frente a supuestos fenómenos de saqueo, de omisión o de quema de las fuentes originales en el marco de los conflictos culturales e ideológicos del mundo clásico.

\section{REFERENCIAS BIBLIOGRÁFICAS}

'ABD AL-Raب̣mān, Ṭāhā (1995): Fiqh al-tarğama. Alfalsafa wa-l-tarğama, Casablanca: al-Markaz alTaqāfī al-'Arabī.

Adonis ('Alī Ahmad Sa'īid) (1978): Al-Tāảbit wa-l-

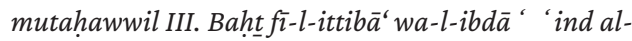
'arab, Beirut: Dār al- 'Awda.

Amīn, Ahmad (2011a [1928]): Fağr al-islām, El Cairo: Hindāwī.

Amīn, Aḥmad (2011b [1933]): Ḍuhà al-islām, El Cairo: Hindāwī.

CORÁN (19924): El Corán, trad. Julio Cortés, Barcelona: Herder.

AL-DuBYān, Aḥmad (1993): Hunayn Ibn Ishāàq. Dirāsa tārīhiyya wa-lugawiyya, Riad: Maktabat al-Malik Fahd al-Wațaniyya.

EI (1960): Encyclopédie de l'Islam, París: G. -P. Maisonneuve.

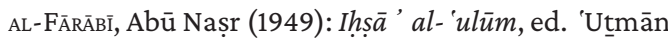
Amīn, El Cairo: Dār al-Fikr al-'Arabī.

AL-ĞĀBIRĪ, Muḥammad 'Ābid (2009): Naqd al-'aql al'arabī (I). Takwīn al-'aql al-'arabī, Beirut: Markaz Dirāsāt al-Wahda al-'Arabiyya. 10. ${ }^{\mathrm{a}} \mathrm{ed}$.

AL-ĞĀBIRĪ, Muhammad 'Ābid (2000): Naqd al-'aql al'arabī (II): Binyat al-'aql al-'arabī, Casablanca: Dār al-Našr al-Magribiyya. 7. ${ }^{\mathrm{a}}$ ed.

AL-ĞĀḤIZ, Abū 'Uțāān 'Amr (1998): al-Bayān wa-ltabyīn, crítica textual de 'Abd al-Salām Muhammad Hārūn, (7. a ed.), El Cairo: Maktabat al-Jānŷī.

GuTAS, Dimitri (1998): Greek Thought, Arabic Culture. The Graeco-Arabic Translation Movement in Baghdad and Early 'Abasid Society $\left(2^{\text {nd }}-4^{\text {th }} / \mathcal{8}^{\text {th }}-10^{\text {th }}\right.$ centuries), London: Routledge.

Hourani, Albert (1992): Historia de los pueblos árabes, trad. Blanca Ribera de Madariaga, Barcelona: Ariel. IBN AL-NADĪM, Abū al-Farağ Muhammad (s. d.): Al-Fihrist, Beirut: Dār al-Ma'rifa li-1-Tỉbā'a wa-1-Našr.

Iвn Ḥ̂AM, Abū Muhammad 'Alī (1987²): Al-Rasā 'il, ed. Ihsān 'Abbās, Beirut: al-Mu' assasa al-'Arabiyya li1-Dirāsāt wa al-Našr.

[IBn Jaldún] Ibn Huladūn, 'Abd al-Raḥmān (2004): $M u$ qaddima, ed. 'Abd Allāh Muhammad al-Darwīš, Damasco: Dār al-Balhīi.

'ItмĀN, Ahmad (2013): Al-Munğaz al-'arabī al-islāmī 
452 fì l-tarğama wa-ḥiwār al-țaqāfāt min Bag̀dād ilà Ṭlaytila, El Cairo: al-Hay'a al-Mișriyya al-'Āmma li-1-Kitāb.

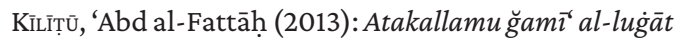
lākin bi-l-'arabiyya, trad. 'Abd al-Salām Ibn 'Abd al'Ālī, Casablanca: Dār Tūbqāl.

Lacoue-Labarthe, Philippe y Jean-Luc Nancy (1978): L'Absolu littéraire. Théorie de la littérature du romantisme allemand, París: Editions du Seuil.

AL-MAS 'ŪDī, Abū 1-Ḥasan (2005): Murū $\breve{g} a l-\underline{d} a h a b$ wa ma'ādin al-ğawhar I, ed. Kamāl Hasan Mur'ī, Beirut: al-Maktaba al-'Așriyya.

Samsó, Julio (20112): Las Ciencias de los Antiguos en alÁndalus, Almería: Fundación Ibn Tufayl de Estudios árabes.

ṬARĀBĪ̄̌Ī, Georges (2006): Harțaqāt. 'An aldìmuqrātiyya wa-l- 'ilmāniyya wal-hadāta wa-lmumāna 'a al- 'arabiyya, Beirut: Dār al-Sāqī.

AL-TAWHīDĪ, Abū Ḥayyān (1929): Al-Muqābasāt, ed. Ḥasan al-Sandūbī, El Cairo: al-Mațba'a alRaḥmāniyya. 